\title{
Promotion of Language Skills in Preschool Children in a Context of Low Educational Standards
}

\author{
Tatiana Pontrelli Mecca1, Patrícia Botelho da Silva², Roselaine Pontes de Alemida², \\ Camila Rennhard ${ }^{2}$, Jucélia Santos Ganz ${ }^{3}$, Luce Malba Campos ${ }^{3}$, \\ Elizeu Coutinho de Macedo ${ }^{2}$ \\ ${ }^{1}$ Educational Psychology Program at Unifieo, Osasco, Brazil \\ ${ }^{2}$ Developmental Disorders Program, Mackenzie University, Sao Paulo, Brazil \\ ${ }^{3}$ Neurocenter, Sao Luis do Maranhão, Brazil \\ Email: tati.mecca@gmail.com
}

Received 4 June 2015; accepted 17 July 2015; published 20 July 2015

Copyright (C) 2015 by authors and Scientific Research Publishing Inc.

This work is licensed under the Creative Commons Attribution International License (CC BY).

http://creativecommons.org/licenses/by/4.0/

(c) (i) Open Access

\section{Abstract}

This study aims to evaluate the effectiveness of an intervention program for preschool children in an area where educational standards are poor. The participants, 129 children aged between 3 and 6 years, belonging to a public kindergarten in a Brazilian state with the second lowest human development index were involved in this research. The children were divided into an experimental intervention group and control group, where intelligence, memory, vocabulary, rapid automatized naming, and phonological awareness were evaluated before and after an intervention. The results show improvements in receptive vocabulary and rapid automatized naming in the experimental group after intervention. The level of intelligence prior to intervention was able to predict $25 \%$ of the vocabulary performance after intervention. Phonological awareness was predictive to nearly $26 \%$ of the performance in vocabulary after intervention only in the experimental group.

\section{Keywords}

Vocabulary, Intelligence, Memory, Rapid Automatized Naming, Phonological Awareness

\section{Introduction}

Interventions in preschool have significant effects on cognitive and socio-emotional development (Domitrovich

How to cite this paper: Mecca, T. P., da Silva, P. B., de Alemida, R. P., Rennhard, C., Ganz, J. S., Campos, L. M., \& de Macedo, E. C. (2015). Promotion of Language Skills in Preschool Children in a Context of Low Educational Standards. Psychology, 6, 1125-1135. http://dx.doi.org/10.4236/psych.2015.69110 
et al., 2013), which have a subsequent impact on school performance in later years (McClelland, Acock, \& Morrison, 2006). Developing high-quality intervention programs during preschool provides increasing evidence for the general improvement of children's standardized intelligence scores, reduction of school year repetition, and decreases the number of students in special education programs (Nisbett, 2010). Their benefits also seem to influence long-term outcomes (Cunha \& Heckman, 2011; Heckman, Moon, Pinto, Savelyev, \& Yavitz, 2010), such as better high school graduation rates (Nisbett, 2010), lower incidences of criminal activity, better employment rates (Golembeski \& Fullilove, 2005; Heckman et al., 2010; Muennig, Schweinhart, Montie, \& Neidell, 2009), improvements in health outcomes in later life, and longevity (Muennig, 2014). Such findings reinforce the supremacy of early and preventive intervention programs in preschoolsto the detriment of late intervention programs, which tend to be more costly and produce less promising results (Cunha \& Heckman, 2011).

Data obtained from the National Early Literacy Panel (NELP) held in 2008 points to 11 predictive abilities for the subsequent development of literacy in monolingual children up to 5 years old. Among the highlighted abilities are knowledge of the alphabet, phonological awareness, rapid automatized naming (for objects, letters, numbers, and colors), writing of names or single letters, and phonological memory. These abilities showed a high predictive power for reading development regardless of IQ variations and socio-economic status. The others, such as conceptions of what is being seen (front and back; letter or drawing), early decoding, vocabulary and memory, oral language (understanding spoken language), and the process of visual discrimination, have moderate effects and do not hold predictive power when contextual variables are controlled. Results from intervention studies on language skills and reading (Vellutino, Scanlon, \& Zhang, 2007) show their significant effect for children with and without language difficulties and thus everyone can participate in preventive learning interventions (O’Connor, Bocian, Beebe-Frankenberger, \& Linklater, 2010).

Response to intervention (RTI) (Batsche et al., 2005) is considered to be one of the most effective models for preventive level intervention programs. RTI is an approach to prevent and remediate learning difficulties through interventions by teachers in schools. It allows the early identification of children with academic and behavioral problems, monitorsthe progress of these children, and can offer interventions that vary in levels of intensity (Fletcher \& Vaughn, 2009). The model for early childhood education has been called K-RTI and emphasizes the prevention of future problems in literacy (Coleman, Froma, \& West, 2009; Bowyer-Crane, Snowling, Duff, \& Hulme, 2011) by showing its effectiveness for developing and promoting language and meta-linguistic skills (Aguilar-Mediavilla, Buil-Legaz, Perez-Castello, Rigo-Carratala, \& Adrover-Roig, 2014; Georgiou, Tziraki, Manolitsis, \& Fella, 2013; Kieffer, 2012; Noe, Spencer, Kruse, \& Golstein, 2014; Silke et al., 2013; Spencer et al, 2013; Vellutino, Scanlon, \& Zhang, 2007).

Studies examining the effectiveness of programs that promote language development and other predictive skills of reading and writing have been conducted in different languages, such as Spanish (Aguilar-Mediavilla et al., 2014) and Greek (Georgiou et al., 2013), but the majority are done in English (McClelland, Acock, \& Morrison, 2006; Silke et al., 2013; Noe et al., 2014). However, there are still few studies on early intervention programs of a preventive nature aimed at the promotion of Portuguese language skills (Almeida, 2012).

According to a report from the Organization for Economic Co-operation and Development (OECD, 2012), the performance of Brazil, the largest Portuguese-speaking country in the Program for International Student Assessment (PISA), is below the world average and is comparable to countries like Colombia, Tunisia, and Uruguay. In fact, among Latin American countries Brazil performs below Chile, Costa Rica, and Mexico. About 50\% of Brazilian students performed below the baseline level of proficiency, meaning that, at best, they can recognize the purpose of an author's writing or the main theme of a text about a familiar topic and make a simple connection between information in the text and everyday knowledge.

We also emphasize the fact that the Brazilian states with the lowest Human Development Index (HDI) are also those with the lowest educational attainment. According to the United Nations Development Program (UNDP), the State of Maranhão has the second lowest HDI in the country. Information from the Human Development Atlas in Brazil (United Nations [UN], 2010) shows that 31.42\% of children in Maranhão are extremely poor, the illiteracy rate from 11 to 14 years old is $7.59 \%$, and that this rate increases to $20.87 \%$ after 15 years of age. Given this context and the fact that children who grow up in poverty are significantly more likely to experience delays in various aspects of development, of which language is one (Domitrovich et al., 2013), this study aims to verify the performance of children from public kindergartens in cognitive tasks before and after the implementation of a preventive intervention program for the development of language skills. 


\section{Method}

\subsection{Participants}

The study included 129 children without delays in development, ranging from 3 to 6 years old $(\mathrm{M}=4.35, \mathrm{SD}=$ 0.90), who belong to kindergartens in the Maranhão state. Participants were divided into an experimental group (EG) and control group (CG) and matched by age, sex, and type of school (central and peripheral). Table 1 shows the sample distribution according to these variables.

Children were excluded if they had sensory, physical, or intellectual impairments according to the school records. In addition to informed consent authorization from adults responsible for children and the institutions where data collection occurred, only children who volunteered to be part of this study participated in this evaluation.

\subsection{Instruments}

The Columbia Mental Maturity Scale (CMMS) assesses the overall capacity for reasoning, primarily to discern the relationships between various types of pictures in children aged from 3 years and 6 months to 9 years and 11 months. These are skills that are important for success in school. The child must choose the picture that is different or does not relate to others, and therefore find the underlying rule that organizes the pictures (Burgemeister, Blum, \& Lorge, 1971).

The Memory Test for Preschoolers (MTP) evaluates the memory of children aged between 3 and 6 years old, which allows the manipulation of information through verbal and visual stimuli. In total, 4 tests were given. In the first the child must repeat the same sequence of words presented orally by the examiner. In the second, the child hears a sequence of words and must point to the stimuli on the board that has the same sequence. In the third test, the evaluator presents a sequence of pictures and the child must respond verbally to the name of the stimuli in the same sequence in which they were presented. Finally, in the last test a sequence of stimuli is visually presented and the child must point to the drawings on a board in the same sequence in which they were presented (Duarte, Covre, Braga, \& Macedo, 2011).

The Rapid Automatized Naming Test (RAN) is administered individually and evaluates the individual's ability to see a visual picture and name it. It takes into account both the accuracy and speed of the nomination. The test is divided into four tests: naming colors, objects, letters, and numbers (Wolf \& Denckla, 2005). There is a Brazilian adaptation for the test because it includes a high frequency of Portuguese language stimuli. The number of errors and the total time for naming all items on the board are computed unlike the original version of the

\begin{tabular}{lcc} 
Table 1. Characteristics of the sample by age, gender, and school. \\
\hline Variables & & Participants \\
\hline & 3 & No. (\%) \\
Age & 4 & $20(15.5)$ \\
& 5 & $63(48.8)$ \\
& 6 & $28(21.7)$ \\
Gender & Male & $18(14)$ \\
& Female & $66(51.16)$ \\
School group & EG $^{*}$ & $63(48.84)$ \\
& CG $^{*}$ & $74(57.36)$ \\
Area & Central area & $55(42.64)$ \\
& peripheral area & $67(51.93)$ \\
\hline
\end{tabular}

${ }^{*} \mathrm{EG}=$ experimental group; CG = control group. 
test, where only the total time of named items is taken into account. Moreover, only a sub-test was used for naming objects. Children presented effect floor so there was no variability in the data specifying be a very difficult test.

The Peabody Picture Vocabulary Test (PPVT) provides an estimate of the auditory-receptive verbal abilities of children aged from 2 years and 6 months to 18 years of age. The test consists of 144 items and is used to evaluate receptive vocabulary of preschool children (Capovilla \& Capovilla, 1997; Dunn \& Dunn, 1981). It also presents sensitivity when discriminating successive levels of age and schooling (Macedo et al., 2006).

The Phonological Awareness Test by Oral Production (PAT-OP) evaluates the ability to manipulate sounds of speech. It consists of 10 sub-tests that measure different levels of phonological awareness: syllabic synthesis, phonemic synthesis, judgement of alliteration, syllabic segmentation, phonemic segmentation, syllabic manipulation, phonemic manipulation, syllabic transposition, and phonemic transposition. The test lasts approximately 25 minutes (Seabra \& Capovilla, 2012).

\subsection{Procedures}

This project was submitted and approved by the Research Ethics Committee of the University of Mackenzie. After this stage, contact with schools was made to request the permission of the institution's management and informed consent forms were sent to parents and children to request their participation in the research.

The sample was selected for convenience according to the location. Data collection was conducted in four schools, two located at the center and the other two on the outskirts of the city. The application of the instruments was held in schools during the class period, as previously agreed with the institution in order to not affect the activities and routine of the students. The evaluations were performed before and after the interventions with individual children, and the duration to answer all the instruments was between 40 to 50 minutes.

The "Activamente” program (Ganz, Campos, \& Almeida, 2013) presents activities that involve naming pictures and objects, their characteristics and functional properties for children of 3 and 4 years of age. For children of 5 and 6 years, the activities also involved the development of semantic categorization and associations with stimuli. It is worth pointing out that, despite the fact that the program's activities had been developed with a focus on vocabulary and specific instruments were selected for the evaluation of oral language skills, other abilities such as memory and intelligence were also tested. This will be investigated if other abilities can also be developed from the intervention.

Teachers belonging to the kindergartens in the experimental group participated in a training course of 16 hours, divided into 4 periods of 4 hours. The training consisted of lectures on human development, the importance of early stimulation, theories of learning, and practical lessons on strategies to stimulate the development of language skills. They also received a booklet with texts that substantiate the theoretical discussions and handouts about stimulation, which contained 40 activities for this age group that aimed to develop oral language skills. The activities were planned based on the literature and considered other intervention programs developed for this age group. Teachers belonging to the kindergarten of the control group received no instruction.

After the training course, teachers were instructed to insert stimulus activities from the handouts three times a week in their work routine for a period of four months. To this end, they received the aid of researchers from the project to organize a schedule that saw the systematization of different abilities to be stimulated and implementation of activities in order of increasing difficulty.

Throughout the intervention process, two of the researchers responsible for the study visited the schools (once or twice a month) to monitor the project and compliance with the previously established implementation schedule. These meetings were also characterized by opportune moments to talk with teachers about the program and clarify any doubts about intervention activities.

\section{Data Analysis}

Descriptive and inferential statistics were performed on IBM SPSS software, version 21.0. The level of significance for the interpretation of the analysis was $5 \%(p \leq .05)$. Before the intervention, the performance of students in the EG and CG was compared by the following criteria: intelligence, memory, vocabulary, rapid automatized naming, and phonological awareness. Intra-group comparison was made to see if there were differences in the performance of the groups between the first and second evaluation. Finally, the performance of the experimental and control groups were compared after 16 weeks of intervention. 
The Kolmogorov-Smirnov values were checked to verify that the data was normally distributed and the Levene test was used to verify the variances' homogeneity. The criterion used to consider the sample homogeneous and with a normal distribution was $p$ value above .05 in both the Kolmogorov-Smirnov and Levene test. Due to the non-normal distribution of data and non-homogeneity of variances that are necessary assumptions for the use of parametric tests, non-parametric tests were performed and analyzed.

The Wilcoxon test was used for intra-group comparison before and after intervention and the Mann-Whitney test to compare the experimental and control groups. After the intervention, Spearman's correlation analysis was performed for the differences in performance between the CMMS and language tests PPVT, RAN, and PAT-OP. In order to verify the effects of intelligence and phonological awareness ability for subsequent performances in receptive vocabulary tests regression analysis was performed.

\section{Results}

Firstly, descriptive statistics are presented for the performance of the participants in the experimental and control groups before and after intervention. Table 2 shows the mean values, standard deviation, and median, according to group and the time of evaluation.

Comparison analysis was performed for the groups using the Columbia Mental Maturity Scale test, Memory Test for Preschoolers, Rapid Automatized Naming Test, Peabody Picture Vocabulary Test, and Phonological Awareness Test by Oral Production. The results of the evaluation before the implementation of the intervention program are summarized in Table 3.

According to the test of the children's performance before the intervention, the results obtained and described in Table 3 show that there is no statistically significant differences between the experimental and control groups in terms of intelligence, memory, vocabulary, and rapid automatized naming (time and errors). However, there was a statistically significant difference between the better performing EG and the CG in the PAT-OP.

Given the similarity between the groups(except for phonological awareness),we proceeded to compare the analysis between them after 16 weeks of intervention activities for oral language development. The post-intervention results obtained from the Mann-Whitney test are shown in Table 4.

According to the results obtained from the comparison between groups, the Mann-Whitney test showed that after the intervention the EG presented a superior performance that was statistically significant when compared

Table 2. Mean values, standard deviation, and median for the evaluation of the groups' ability.

\begin{tabular}{cccccc}
\hline \multirow{2}{*}{ Variables } & Group & \multicolumn{2}{c}{ Pre } & \multicolumn{2}{c}{ Post } \\
\cline { 3 - 6 } Intelligence (CMMS) & EG & $116.66(17.6)$ & 116 & $121.19(20.91)$ & 118 \\
& CG & $110.60(27.7)$ & 112 & $115.80(16.13)$ & 119 \\
Memory (MTP) & EG & $5.32(2.78)$ & 5 & $5.03(2.36)$ & 5 \\
CG & $4.46(2.55)$ & 4 & $4.53(1.88)$ & 5 \\
Receptive vocabulary \\
(PPVT)
\end{tabular}


Table 3. Results of the Mann-Whitney test to compare pre-intervention groups.

\begin{tabular}{|c|c|c|c|c|c|}
\hline Variables & Group & Mean rank & Sum of ranks & $\mathbf{U}$ & $\boldsymbol{P}$ \\
\hline \multirow[b]{2}{*}{ Intelligence (CMMS) } & EG & 16.860 & 354.000 & \multirow[b]{2}{*}{87.000} & \multirow[b]{2}{*}{.446} \\
\hline & CG & 14.200 & 142.000 & & \\
\hline \multirow{2}{*}{ Memory (MTP) } & EG & 26.600 & 904.500 & \multirow{2}{*}{200.500} & \multirow{2}{*}{.231} \\
\hline & CG & 21.370 & 320.500 & & \\
\hline \multirow{2}{*}{$\begin{array}{l}\text { Receptive vocabulary } \\
\text { (PPVT) }\end{array}$} & EG & 21.170 & 550.500 & \multirow{2}{*}{190.500} & \multirow{2}{*}{.903} \\
\hline & CG & 20.700 & 310.500 & & \\
\hline \multirow{2}{*}{ RAN objects-time } & EG & 33.560 & 1644.500 & \multirow{2}{*}{413.500} & \multirow{2}{*}{.965} \\
\hline & CG & 33.320 & 566.500 & & \\
\hline \multirow{2}{*}{ RAN objects-error } & EG & 35.130 & 1721.500 & \multirow{2}{*}{336.500} & \multirow{2}{*}{.237} \\
\hline & CG & 28.790 & 489.500 & & \\
\hline \multirow{2}{*}{$\begin{array}{c}\text { Phonological awareness } \\
\text { (PAT-OP) }\end{array}$} & EG & 18.70 & 430.000 & \multirow{2}{*}{53.000} & \multirow{2}{*}{$.033^{*}$} \\
\hline & CG & 10.89 & 98.000 & & \\
\hline
\end{tabular}

*Significance level of $p \leq .05$.

Table 4. Mann-Whitney test to compare the post-intervention results of the groups.

\begin{tabular}{|c|c|c|c|c|c|}
\hline Variables & Group & Mean rank & Sum of ranks & $\mathbf{U}$ & $\boldsymbol{P}$ \\
\hline \multirow{2}{*}{ Intelligence (CMMS) } & EG & 16.550 & 347.500 & \multirow{2}{*}{93.500} & \multirow{2}{*}{.627} \\
\hline & CG & 14.850 & 148.500 & & \\
\hline \multirow{2}{*}{ Memory (MTP) } & EG & 24.940 & 823.000 & \multirow{2}{*}{233.000} & \multirow{2}{*}{.744} \\
\hline & CG & 23.530 & 353.000 & & \\
\hline \multirow{2}{*}{ Receptive vocabulary (PPVT) } & EG & 25.350 & 659.000 & \multirow{2}{*}{82.000} & \multirow{2}{*}{.002} \\
\hline & CG & 13.470 & 202.000 & & \\
\hline \multirow{2}{*}{ RAN objects-time } & EG & 35.580 & 1743.500 & \multirow{2}{*}{314.500} & \multirow{2}{*}{.135} \\
\hline & CG & 27.500 & 467.500 & & \\
\hline \multirow{2}{*}{ RAN objects-error } & EG & 31.870 & 1561.500 & \multirow{2}{*}{336.500} & \multirow{2}{*}{.234} \\
\hline & CG & 38.210 & 649.500 & & \\
\hline \multirow{2}{*}{$\begin{array}{l}\text { Phonological Awareness } \\
\text { (PAT-OP) }\end{array}$} & EG & 17.04 & 392.000 & \multirow{2}{*}{91.000} & \multirow{2}{*}{.598} \\
\hline & CG & 15.11 & 136.000 & & \\
\hline
\end{tabular}

*Significance level of $p \leq .05$.

to the CG in the vocabulary test. The same was not observed in relation to intelligence, memory, errors, and time spent on the rapid automatized naming test. This indicates that the language activities for the EG were effective in promoting specific receptive vocabulary.

As previously mentioned, groups did not present statistically significant differences between performances in the CMMS before and after intervention. However, analysis of Spearman's correlation showed a positive, significant relationship of moderate magnitude between intelligence and receptive vocabulary in the EG after intervention (rho $=.59 ; p \leq .001$ ). However, this relationship was not observed before the intervention (rho $=.31$, 
$p=.146$ ), indicating that while the intervention has no effect on intelligence, it is an important variable to be considered in terms of its relationship with receptive vocabulary after intervention. Regression analysis showed that level of intelligence before intervention predicts $37 \%$ of the performance in receptive vocabulary after intervention, as confirmed by the data presented in Table 5 .

The EG's performance in the CMMS correlated negatively, with a significant and moderate magnitude, to times in the RAN task (rho $=-.52, p=.002$ ), indicating an association between intelligence and less time taken (higher speed) in the rapid automatized naming of objects before intervention. This relationship was also observed after intervention ( $r$ o $=-.44, p=.004)$.

The results obtained in the pre-intervention assessment show the better performance of the EG inphonological awareness test when compared to the CG. In this regard, the predictive value for later performance ability in vocabulary tasks (post-intervention) in both groups was found. The results are summarized in Table 6.

The results from the linear regression analysis showed that only the EG's phonological awareness skills significantly predict subsequent performance in vocabulary. Performance in the PAT-OP was a predictor of almost $26 \%$ of the vocabulary performance in the EG. According to the results presented in Table 6, it is noted that the same was not observed in the CG.

In addition to the comparison between groups, an intra-group analysis was performed in order to better understand the possible gains of intervention. Results are presented separately for each group. Table 7 shows the results obtained from comparing each of the abilities of the EG pre- and post-intervention.

The data presented in Table 7 shows that there was a statistically significant difference between the EG's performances in the receptive vocabulary test (PPVT) pre- and post-intervention. Superior performance was observed after the intervention. The same was observed with respect to the times for completing the rapid automatized naming of objects, where the children spent longer in the first evaluation than the second. A trend was observed only in terms of reducing errors in the RAN test after intervention. Table 8 presents data of the CG's preand post-evaluation.

Table 5. Linear regression results that show intelligence to be a predictor of vocabulary.

\begin{tabular}{ccccccc}
\hline Model & $\mathbf{R}$ & $\mathbf{R}^{2}$ & $\begin{array}{c}\mathbf{R}^{2} \\
\text { adjusted }\end{array}$ & STD. error of estimate & F & $\boldsymbol{P}$ \\
\hline Vocabulary $^{\mathrm{a}}$ & .629 & .396 & .374 & 12.402 & 18.329 & $<.001$ \\
\hline
\end{tabular}

${ }^{\mathrm{a}}$ Performance in CMMS (intelligence) as a predictor of vocabulary (PPVT).

Table 6. Linear regression results that consider phonological awareness as a predictor of vocabulary.

\begin{tabular}{ccccccc}
\hline Model $^{\mathbf{a}}$ & $\mathbf{R}$ & $\mathbf{R}^{2}$ & $\begin{array}{c}\mathbf{R}^{2} \\
\text { adjusted }\end{array}$ & STD. error of estimate & F & $\boldsymbol{P}$ \\
\hline EG & .534 & .285 & .257 & 13.388 & 9.971 & $.004^{*}$ \\
CG & .154 & .024 & -.116 & 15.286 & .171 & .692 \\
\hline
\end{tabular}

${ }^{\mathrm{a}}$ Phonological awareness: independent variable (predictor); vocabulary: dependent variable. ${ }^{*}$ Level of Significance $p \leq .05$.

Table 7. Performance comparison of the EG pre- and post-intervention.

\begin{tabular}{|c|c|c|c|c|c|c|}
\hline \multirow[b]{2}{*}{ Variables } & \multicolumn{2}{|c|}{ Negative ranks } & \multicolumn{2}{|c|}{ Positive ranks } & \multirow[b]{2}{*}{$\mathbf{z}$} & \multirow[b]{2}{*}{$p$} \\
\hline & Mean rank & Sum of ranks & mean rank & Sum of ranks & & \\
\hline Intelligence (CMMS) & 8.940 & 80.500 & 10.950 & 109.500 & .584 & .559 \\
\hline Memory (MTP) & 11.060 & 188.000 & 16.000 & 112.000 & 1.103 & .270 \\
\hline Receptive vocabulary (PPVT) & 5.600 & 28.000 & 15.380 & 323.000 & 3.748 & $.000^{*}$ \\
\hline RAN objects—time & 27.190 & 843.000 & 19.590 & 333.000 & 2.616 & $.009^{*}$ \\
\hline RAN objects-error & 19.480 & 467.500 & 18.120 & 235.000 & 1.756 & .079 \\
\hline Phonological awareness (PAT-OP) & 9.43 & 66.00 & 10.33 & 124.00 & 1.172 & .241 \\
\hline
\end{tabular}

${ }^{*}$ Level of significance $p \leq .05$. 
Table 8. Performance comparison of the CG pre- and post-intervention.

\begin{tabular}{ccccccccc}
\hline & \multicolumn{2}{c}{ Negative ranks } & \multicolumn{2}{c}{ Positive ranks } & & \\
\hline Variables & Mean rank & Sum of ranks & Mean rank & Sum of ranks & $\mathbf{z}$ & $\boldsymbol{P}$ \\
\hline Intelligence (CMMS) & 5.000 & 25.000 & 6.000 & 30.000 & .255 & .798 \\
Memory (MTP) & 5.330 & 32.000 & 6.800 & 34.000 & .090 & .929 \\
Receptive vocabulary(PPVT) & 9.640 & 67.500 & 6.560 & 52.500 & .426 & .670 \\
RAN objects—time & 11.860 & 130.500 & 3.750 & 22.500 & 2.557 & $.011^{*}$ \\
RAN objects-error & 10.750 & 64.500 & 8.050 & 88.500 & .569 & .569 \\
Phonological Awareness (PAT-OP) & 3.50 & 7.000 & 5.43 & 38.000 & 1.849 & .064 \\
\hline
\end{tabular}

*Level of Significance $p \leq .05$.

According to Table 8, the results of the comparison of performance before and after the intervention in the CG showed no statistically significant difference in intelligence, memory, and the errors in rapid automatized naming. However, as in the EG, there was a significant decrease in the time spent on the RAN test in the second evaluation.

\section{Discussion}

The objective of this study was to implement an intervention program for public kindergarten preschool children in a Brazilian city, whose illiteracy rates and socio-economic conditions have been one of the lowest in the country (UN, 2010). The program was developed with a focus on oral language skills, especially vocabulary, which is one of the skills considered to be a good predictor of later reading (Kieffer, 2012; Spencer, 2013). Conducted by teachers in the classroom, this is a model of early and preventive intervention based on the assumptions of Response to Intervention (Batsche et al., 2005; Fletcher \& Vaughn, 2009).

The activities were designed to develop language abilities (particularly vocabulary), since the literature reports the relevance of promoting these abilities in preschool children (Aguilar-Mediavilla et al., 2014; Georgiou et al., 2013; Noe et al., 2014; Silke et al., 2013). Moreover, the role they have in the later development of reading and writing skills (Aguilar-Mediavilla et al., 2014; Kieffer, 2012; Skibbe et al., 2008) justifies the relevance of this study.

Initially (pre-intervention), the EG and CG groups were compared with respect to oral language abilities such as vocabulary, rapid automatized naming (errors and time), and phonological awareness, as well as other cognitive abilities like intelligence and memory. There was no statistically significant difference between the groups in most of the evaluated abilities (except in phonological awareness), and an improved performance was observed in the GE. Moreover, the results obtained after the intervention showed no significant difference between groups in the PAT-OP, apart from receptive vocabulary, where the EG showed an improved performance.

The improvement in receptive vocabulary confirms other findings that show an increase in performance in vocabulary tasks in preschool after interventions directed at the development of oral language (Coleman, Froma, \& West, 2009; Spencer, 2013). The difference in performance between groups for intelligence, memory, rapid automatized naming, and phonological awareness were not verified. These results reflect the performed activities since they had the main objective of developing vocabulary. In the activities program, there was not an activity to work processing speed, which is an important skill for performing rapid automatized naming. Few activities demanded the manipulation of letters and sounds. This shows that the program fulfilled its primary role in the development of vocabulary, but the effect was not extended to other abilities.

It was also observed that performance on the vocabulary test (PPVT) presented a positive and significant correlation of a moderate magnitude with the intelligence test (CMMS) after intervention. This result validates previous findings as vocabulary skills are associated with intelligence levels (Nisbett et al., 2012). The importance of this relationship is verified in the predictor effect of intelligence (pre-intervention) in vocabulary performance after intervention. The results showed that this was able to significantly predict approximately $37 \%$ of the subsequent performances in vocabulary. This data shows that individual cognitive differences must be considered 
even in collective intervention procedures.

In this study, intelligence was also associated with speed in the RAN task before and after intervention. The negative and significant correlations show that children with the highest scores in the CMMS featured shorter times in naming task, that is, they had better abilities when naming objects. This relationship between processing speed and intelligence was expected since the former was referred to as one of the components of the second (Schneider \& McGrew, 2012).

Phonological awareness is another variable that is predictive of subsequent vocabulary performance. As the groups showed significant differences before the intervention, with a better performance in the EG, it became clear that this skill was able to predict the improvement observed in vocabulary in the EG. The results showed that only the EG's phonological awareness abilities were able to significantly predict approximately $26 \%$ of the vocabulary performance.

Intra-group comparisons were also made and indicated that both the EG and the CG showed better shorter time in naming task after intervention. The improvement in naming speed in both groups can be explained in terms of developing maturity and familiarity with the stimulus, since the children had already been exposed to the same test broads from the pre-evaluation. This familiarity has an effect on the processing speed of stimulus, since the information was not new for the child. In fact, words learned earlier are more rapidly named than newly learned words, because lexical access is better facilitated. Thus, vocabulary is a psycholinguistic variable influencing speed and accuracy when naming objects as well as lexical processing skills (Palmer \& Havelka, 2010).

When verifying the effect of the intervention separately in each group, it was found that a better performance was not displayed before and after intervention interests of intelligence, memory, and in the number errors during naming. However, in the control group there was a trend towards improvement in phonological awareness skills.

From the evaluated skills, only the EG's vocabulary skills were superior after intervention, while the same development was not observed in the CG. Thus, the present study showed the promotion of receptive vocabulary in preschool children, an ability that has shown its importance as a predictor of future academic abilities such as reading and writing (Kieffer, 2012; Spencer, 2013).

\section{Conclusion}

This is the first Brazilian study of early and preventive intervention in language skills with preschoolers based on Response to Intervention and the first preliminary study about the "Ativamente" program to promoting language skills in preschool children. The results show the importance of targeted programs that can be developed in classrooms by teachers to benefit all children.

The intervention was conducted by teachers in the classroom. This study indicated the importance of activities for the development of Portuguese vocabulary for preschool children in a country where illiteracy rates are high and the HDI low. Specifically, the results reveal the importance of promoting language skills in children with low background.

The fact that the CG did not receive any type of instruction was a limitation of the study, and this variable should be considered in future studies. The absence of differences in performance between groups and intragroup in other skills points to the main effect of the intervention mainly on vocabulary.

\section{References}

Aguilar-Mediavilla, E., Buil-Legaz, L., Perez-Castello, J. A., Rigo-Carratala, E., \& Adrover-Roig, D. (2014). Early Preschool Processing Abilities Predict Subsequent Reading Outcomes in Bilingual Spanish-Catalan Children with Specific Language Impairment (SLI). Journal of Communication Disorders, 50, 19-35. http://dx.doi.org/10.1016/j.jcomdis.2014.03.003

Almeida, R. P. (2012). Prevenção e remediação das dificuldades de aprendizagem: adaptação do modelo de Resposta à Intervenção numa amostra brasileira. [Prevention and Remediation of Learning Difficulties: Adaptation of Response to Intervention Model in a Brazilian Sample]. Master’s Thesis, Sao Paulo: Universidade Federal de São Paulo.

Batsche, G., Elliott, J., Graden, J. L., Grimes, J., Kovaleski, J. F., Prasse, D., Schrag, J., \& Tilly, W. D. (2005). Response to Intervention: Policy Considerations and Implementation. Alexandria, VA: National Association of State Directors of Special Education, Inc. 
Bowyer-Crane, C., Snowling, M. J., Duff, F., \& Hulme, C. (2011). Response to Early Intervention of Children with Specific and General Language Impairment. Learning Disabilities: A Contemporary Journal, 9, 107-121.

Burgemeister, B., Blum, L., \& Lorge, I. (1971). Columbia Mental Maturity Scale. New York, NY: Harcout, Brace \& Ovanovich.

Capovilla, F. C., \& Capovilla, A. G. S. (1997). Language Development in Children from 2 to 6 Years of Age: Brazilian Translation and Norms for Dunn \& Dunn's Peabody Picture Vocabulary Test and Rescorla's Language Development Survey de Rescorla. Ciência Cognitiva: Teoria, Pesquisa e Aplicação, 1, 353-380.

Coleman, M. R., Froma, R. R., \& West, T. (2009). Road Map to Pre-K-RTI. Applying Responses to Intervention in Preschool Settings. National Center for Learning Disabilities, 13.

Cunha, F., \& Heckman, J. (2011). Capital Humano [Human Capital]. In A. P. Araújo (Org.), Aprendizagem Infantil: Uma abordagem da neurociência, economia e psicologia cognitiva. [Children Learning: An Approach to Neuroscience, Economics and Cognitive Psychology] (pp. 9-33). Rio de Janeiro, RJ: Academia Brasileira de Ciências.

Domitrovich, C. E., Morgan, N. R., Moore, J. E., Cooper, B. R., Shah, H. K., Jacobson, L., \& Greenberg, M. T. (2013). One versus Two Years: Does Length of Exposure to an Enhanced Preschool Program Impact the Academic Functioning of Disadvantaged Children in Kindergarten? Early Childhood Research Quarterly, 28, 704-713. http://dx.doi.org/10.1016/j.ecresq.2013.04.004

Duarte, C. P., Covre, P., Braga, A. C., \& Macedo, E. C. (2011). Visuospatial Support for Verbal Short-Term Memory in Individuals with Down Syndrome. Research in Developmental Disabilities, 32, 1918-1923. http://dx.doi.org/10.1016/j.ridd.2011.03.024

Dunn, L. M., \& Dunn, L. M. (1981). Peabody Picture Vocabulary Test-Revised. Circle Pines, MN: American Guidance Service.

Fletcher, J. M., \& Vaughn, S. (2009). Response to Intervention: Preventing and Remediating Academic Difficulties. Child Development Perspectives, 3, 30-37. http://dx.doi.org/10.1111/j.1750-8606.2008.00072.x

Ganz, J. S., Campos, L. M., \& Almeida, R. P. (2013). Ativamente: Programa de Estimulação Neurocognitiva. “Ativamente”: Neurocognitive Stimulation Program.

Georgiou, G. K., Tziraki, N., Manolitsis, G., \& Fella, A. (2013). Is Rapid Automatized Naming Related to Reading and Mathematics for the Same Reason(s)? A Follow-Up Study from Kindergarten to Grade 1. Journal of Experimental Child Psychology, 115, 481-496. http://dx.doi.org/10.1016/j.jecp.2013.01.004

Golembeski, C., \& Fullilove, R. (2005). Criminal (In)Justice in the City and Its Associated Health Consequences. American Journal of Public Health, 95, 1701-1706. http://dx.doi.org/10.2105/AJPH.2005.063768

Heckman, J. J., Moon, S. H., Pinto, R., Savelyev, P. A., \& Yavitz, A. Q. (2010). The Rate of Return to the High Scope Perry Preschool Program. Journal of Public Economics, 94, 114-128. http://dx.doi.org/10.1016/j.jpubeco.2009.11.001

Kieffer, M. J. (2012). Early Oral Language and Later Reading Development in Spanish-Speaking English Language Learners: Evidence from a Nine-Year Longitudinal Study. Journal of Applied Developmental Psychology, 33, 146-157. http://dx.doi.org/10.1016/j.appdev.2012.02.003

Macedo, E. C., Capovilla, F. C., Duduchi, M., D’antino, M. E. F., \& Firmo, L. S. (2006). Evaluating Receptive Language by Peabody Picture Vocabulary Test: Computerized versus Traditional Versions. Psicologia: Teoria e Prática, 8, 40-50.

McClelland, M. M., Acock, A. C., \& Morrison, F. J. (2006). The Impact of Kindergarten Learning-Related Skills on Academic Trajectories at the End of Elementary School. Early Childhood Research Quarterly, 21, 471-490. http://dx.doi.org/10.1016/j.ecresq.2006.09.003

Muennig, P., Schweinhart, L. J., Montie, J., \& Neidell, M. (2009). Effects of a Pre-Kindergarten Educational Intervention on Adult Health: 37-Year Follow-Up Results of a Randomized Controlled Trial. American Journal of Public Health, 99, 1431-1437. http://dx.doi.org/10.2105/AJPH.2008.148353

Muennig, P. (2014). Can Universal Pre-Kindergarten Programs Improve Population Health and Longevity? Mechanisms, Evidence, and Policy Implications. Social Science \& Medicine, 127, 116-123. http://dx.doi.org/10.1016/j.socscimed.2014.08.033

National Early Literacy Panel (NELP) (2008). Developing Early Literacy: A Scientific Synthesis of Early Literacy Development and Implications for Intervention.

Nisbett, R. E. (2010). Think Big, Bigger... and Smaller. Educational Leadership, 68, 10-15.

Nisbett, R. E., Aronson, J., Blair, C., Dickens, W., Flynn, J., Halpern, D. F., \& Turkheimer, E. (2012). Intelligence: New Findings and Theoretical Developments. American Psychologist, 67, 130-159. http://dx.doi.org/10.1037/a0026699

Noe, S., Spencer, T. D., Kruse, L., \& Goldstein, H. (2014). Effects of a Tier 3 Phonological Awareness Intervention on Preschoolers’ Emergent Literacy. Topics in Early Childhood Special Education, 34, 27-39. http://dx.doi.org/10.1177/0271121413489172 
O’Connor, R. E., Bocian, K., Beebe-Frankenberger, M., \& Linklater, D. L. (2010). Responsiveness of Students with Language Difficulties to Early Intervention in Reading. The Journal of Special Education, 43, 220-235. http://dx.doi.org/10.1177/0022466908317789

Organisation for Economic Co-Operation and Development-OECD (2012). Programme for International Student Assessment (PISA). http://www.oecd.org/pisa/keyfindings/PISA-2012-results-brazil.pdf

Organização das Nações Unidas [United Nations]_ONU (2010). United Nations Development Programme. http://www.pnud.org.br/PNUD_ONU.aspx

Palmer, S. D., \& Havelka, S. (2010). Age of Acquisition Effects in Vocabulary Learning. Acta Psychologica, 135, 310-315. http://dx.doi.org/10.1016/j.actpsy.2010.08.002

Schneider, W. J., \& McGrew, K. S. (2012). The Cattell-Horn-Carroll Model of Intelligence. In D. P. Flanagan, \& P. L. Harrison (Ed.), Contemporary Intellectual Assessment: Theories, Tests and Issues (3rd ed., pp. 553-581). New York: The Guilford Press.

Seabra, A. G., \& Capovilla, F. C. (2012). Prova de consciência fonológica por produção oral [Phonological Awareness Test]. In A. G. Seabra, \& N. M. Dias (Eds.), Avaliação neuropsicológica cognitiva: Linguagem oral [Cognitive Neuropsychological Assessment: Oral Language] (Vol. 2, pp. 117-122). São Paulo, SP: Memnon Edições Científicas.

Silke, F. S., Bowyer-Crane, C., Haley, A. J., Hulme, C., \& Snowling, M. J. (2013). Efficacy of Language Intervention in the Early Years. The Journal of Child Psychology and Psychiatric, 54, 280-290. http://dx.doi.org/10.1111/jcpp.12010

Skibbe, L. E., Grimm, K. J., Stanton-Chapman, T. L., Justice, L. M., Pence, K. L., \& Bowles, R. P. (2008). Reading Trajectories of Children with Language Difficulties from Preschool through Fifth Grade. Language, Speech, and Hearing Services in Schools, 39, 475-486. http://dx.doi.org/10.1044/0161-1461(2008/07-0016)

Spencer, E. J., Goldstein, H., Sherman, A., Noe, S., Tabbah, R., Ziolkowski, R., \& Schneider, N. (2013). Effects of an Automated Vocabulary and Comprehension Intervention an Early Efficacy Study. Journal of Early Intervention, 34, $195-221$. http://dx.doi.org/10.1177/1053815112471990

Vellutino, F. R., Scanlon, D. M., \& Zhang, H. Y. (2007). Identifying Reading Disability Based on Response to Intervention: Evidence from Early Intervention Research. In S. R. Jimerson, M. K. Burns, \& A. Van Der Heyden (Eds.), Handbook of Response to Intervention: The Science and Practice of Assessment and Intervention (pp. 185-211). Heidelberger: Springer Science \& Business Media.

Wolf, M., \& Denckla, M. B. (2005). Rapid Automatized Naming and Rapid Alternating Stimulus Test. Austin, TX: Pro-ed. 